\title{
STATIC AND DYNAMIC LOAD TESTS OF LIBEŇ BRIDGE OVER VLTAVA RIVER IN PRAGUE AND CONCEPT OF REPAIR
}

\author{
PETR TEJ ${ }^{*}$, JAN MOUREK ${ }^{1}$ AND MAREK BLANK ${ }^{1}$
}

\author{
${ }^{1}$ Klokner institute \\ Czech Technical University in Prague (CTU) \\ Šolínova 7, 16000 Prague 6, Czech Republic \\ e-mail: petr.tej@cvut.cz, www.klok.cvut.cz $\left({ }^{*}\right.$ corresponding author)
}

Keywords: Concrete, arch bridge, historical structure, load tests, reconstruction

\begin{abstract}
The Libeň bridge in Prague is a cultural and technical heritage of concrete construction of the beginning from the twentieth century. The bridge was designed by architect Pavel Janák, the founder of cubism in architecture. According to experts, the Libeñ bridge is the only example of cubist morphology application on the bridge structure. Evaluation of Liben bridge structural condition is an up-to-date topic leading to decision whether this bridge should be repaired or replaced by a new bridge. This article deals with the static and dynamic load testing in comparison with following creation and validation of the FEA model for load carrying capacity assessment of the Libeň Bridge and possible way of reconstruction. Paper deals with crucial procedures for FEA model validation of this backfilled arched concrete structure with a focus on the static characteristic of the structure. Article deals with reconstruction of the vault part of the Liben Bridge using R-UHPFRC in terms of static operation. It focuses on the two basic problems of the bridge, the solution to increase the bearing capacity of the vault arches and to increase the bearing capacity of the foundations under pillars. The concept of repair is based on extensive diagnostic surveys conducted in 2017. The concept of structural enhancement is based on adding new thin layer of R-UHPFRC (reinforced, ultra-high performance concrete) on the upper vault surface. Concrete bridge structures are exposed to extreme effects of aggressive environmental influences, especially chlorides, which leads to damaging of most exposed bridge components a long time before their service life. UHPFRC material is suitable for repairs of these structures and especially due to its impermeability and high resistance.
\end{abstract}

\section{INTRODUCTION}

The Libeň Bridge (Figure 1) was built between 1924-1928 according to the design by architect Pavel Janák. The structure was designed by Ing. František Mencl, who was the author of the arch part of the. The bridge was opened to the public on 29 October 1928 on the 10th anniversary of the Czechoslovak Republic with the participation of President Tomas G. Masaryk. Arched spans of three joints from plain concrete are considered to be the highest value of the construction.

The bridge carries urban traffic across inundation area. The width of the communication on the bridge is $14.5 \mathrm{~m}$ (lanes + tram), both sidewalks have a width of $3.25 \mathrm{~m}$. The road cover is 
made of asphalt concrete, the pavements have cast asphalt surface, the tram body is made of concrete panels.

The supporting structure of the arches consists of monolithic concrete segments made of plain concrete with embedded reinforced concrete joints. The vaults are in cross-section divided into 4 segments with a width of $4.85 \mathrm{~m}$. The thickness of the segments is variable - about 0.9 $1.1 \mathrm{~m}$. The vaults are designed as three-joint arches, 2 joints are always located on the cantilever about $3 \mathrm{~m}$ from the edge of the pillars, 1 joint is at the top.

This article focuses on load tests and subsequent assessments of the arched part of the bridge made up of five vaults with backfill. The static action of the vaults is simple - joints at the top and bottom of the vault. In cross-section, the load-bearing structure consists of four vault strips with an approximate width of $4.85 \mathrm{~m}$. The front walls are based on the outer strips, which support the pavement brackets with the railings. In the area above the pillars, the front walls are stiffened by ribs.

Experience with static and dynamic measurement compared to computational models resulting from similar measurements made at the author's workplace on Liben bridge and similar bridge structures [1]-[4]. Experience with designing of bridge structures author obtained participating on several tasks detailly published in articles [5-10].
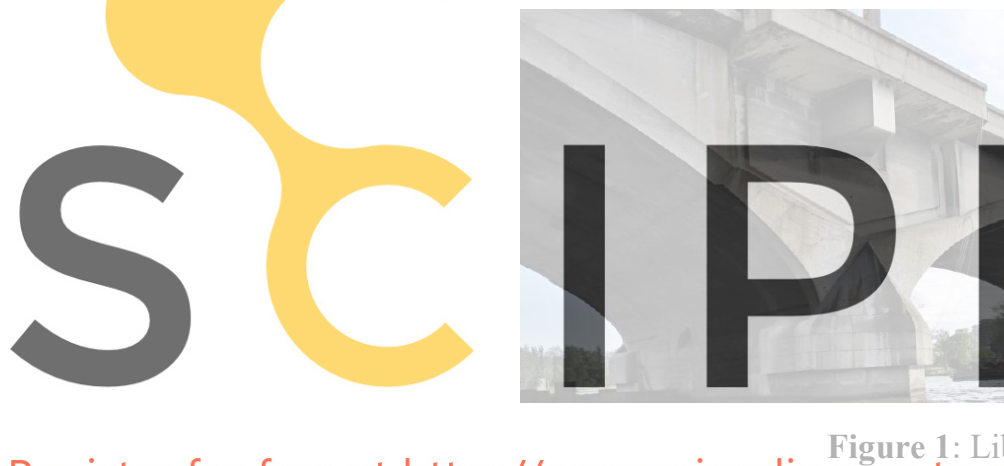

Figure 1: Libeň bridge

Register for free at https//www.scipedia.com to download the version without the watermark

\section{STATIC LOADING TESTS}

Two freight four-axle vehicles with a weight of $40 \mathrm{t}$ have been designed as a test load. The vehicles were placed according to symmetrical load bridge by two lorries at the top of the arcs. Load $2 \times 40 \mathrm{t}$ in the middle of the span in each arc for all 5 arrays $\times 4$ passes, i.e. 20 load cases. In addition, crossings with a vehicle weighing 40 tons were made, in each of the vault strips $3 \mathrm{x}$ back and forth, i.e. 120 crossings.

During the load states the vehicles were in the position as shown in Figure 2, 3 No.1 vehicle (mass $37 \mathrm{t}$ ), the vehicle No. 2 (mass $41 \mathrm{t}$ ) always points in the same direction - ending towards each other and facing to one end of the bridge. For vehicle crossings, both vehicles were used, alternating in the rides individually.

Within the load test, the primary set of measuring points was monitored, which was designed to track field deflections. Secondary set of measuring points, designed to measure support drops, locating movements in support areas, swiveling and pushing and shearing on joints. With the exception of measuring the drops of the supports, all measurements were made electronically (mostly by different variants of inductive sensors). 


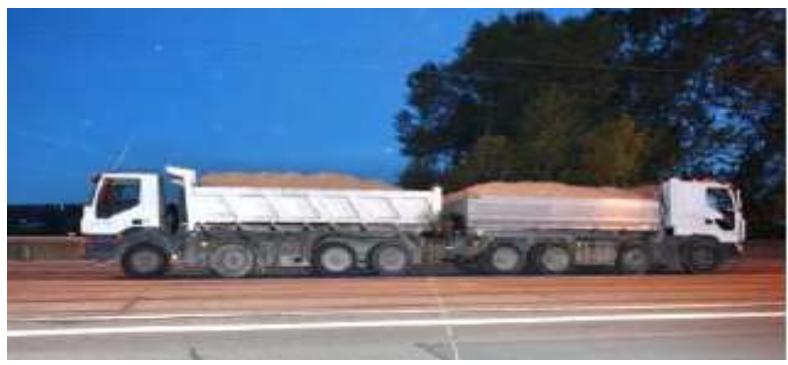

Figure 2: Vehicles during static load test - static

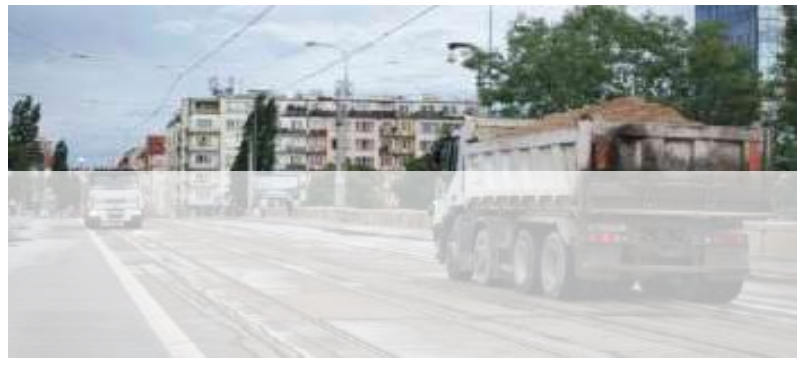

Figure 3: Vehicles during static load test - crossing

\subsection{Conclusion of static load test}

The supporting struc loading and no new unexp clearly con-firmed the interconnected. In this part) and the road and wam-iras
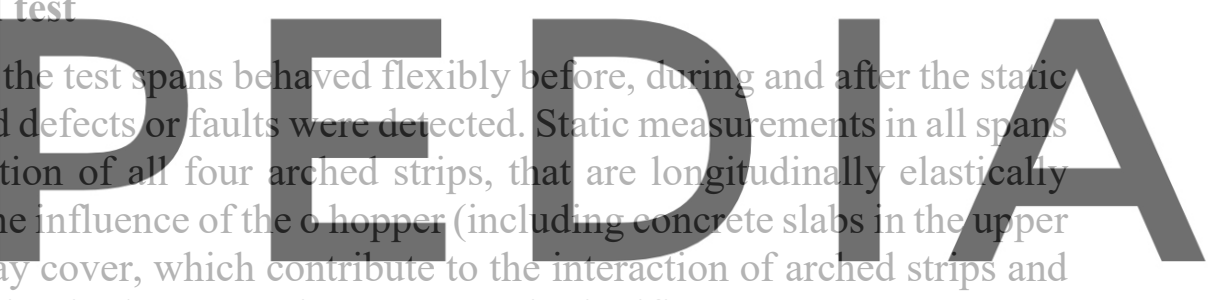

the overall space load distribution in the supporting structure, is significant.

Register for free at https//www.scipedia.com to download the version without the watermark

\section{STATIC ANALYSIS OF THE STRUCTURE}

The computational models were developed in Midas software (Figure 4). The model for assessing the load carrying capacity of vault strips is created using rod, flat, and bulk elements so as to simulate the behavior and dimensions of the structure as close as possible. Due to the complexity of the bridge construction, the overall model is divided into individual vaults, which are then independently assessed.

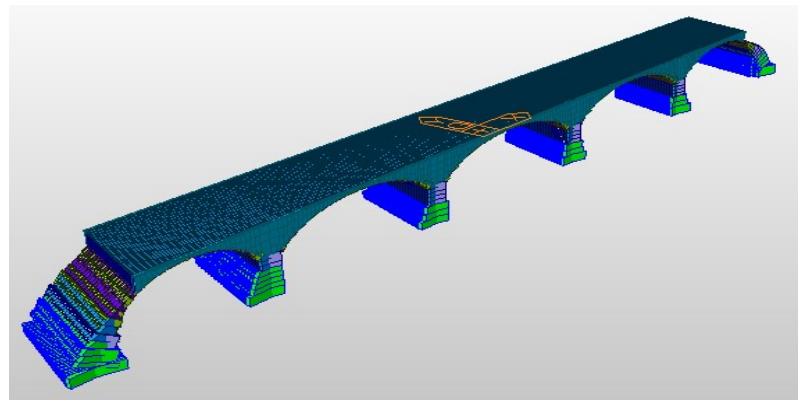

Figure 4: The overall model before dividing into individual parts 


\subsection{Validation of the model}

Validation for temperature effects:

According to the measurements made by precise geodetic measurements, the vertical movement at the top of the longest vault is $\pm 8 \mathrm{~mm}$ when the structure is warmed / cooled by $10^{\circ} \mathrm{C}$. The bridge construction was loaded with the same $\Delta \mathrm{T}$ in the computational model and the vertical deformations at the top of the vault were monitored. The following figures 5, 6 show the values found. From their presentation it is evident that the deformation at the top of the vault exactly corresponds to the measured deformations $\pm 8 \mathrm{~mm}$ for the longest vaults 3 and 4.

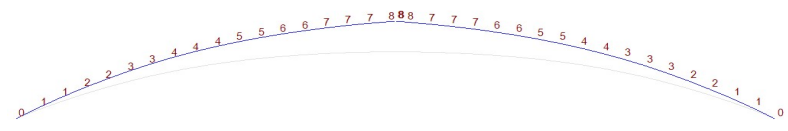

Figure 5: Deformation after the structure is warmed by $+10^{\circ} \mathrm{C}$ on the longest vault

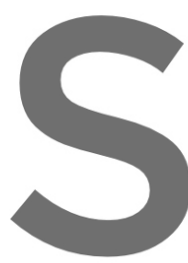

\section{Validation of deflection:}

The models were val strips, especially the concrete at a maximum of the upper slab of the arches of the vault. It is obvious that there is a discontinuity in the top plate at this point

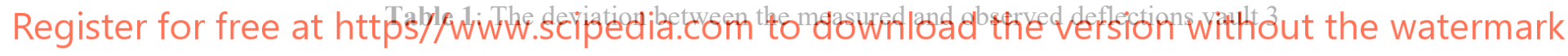

\begin{tabular}{cccc}
\hline $\begin{array}{c}\text { Loaded } \\
\text { strip }\end{array}$ & $\begin{array}{c}\text { Deflection } \\
\text { measured } \\
{[\mathrm{mm}]}\end{array}$ & $\begin{array}{c}\text { Deflection } \\
\text { calculated } \\
{[\mathrm{mm}]}\end{array}$ & $\begin{array}{c}\text { Deviation } \\
{[\%]}\end{array}$ \\
\hline 1 & 1,720 & 1,940 & 11,3 \\
\hline 2 & 1,975 & 1,945 & $-1,5$ \\
\hline 3 & 1,945 & 1,890 & $-2,9$ \\
\hline 4 & 1,945 & 1,914 & $-1,6$ \\
\hline
\end{tabular}

Table 2: The deviation between the measured and observed deflections vault 4

\begin{tabular}{cccc}
\hline $\begin{array}{c}\text { Loaded } \\
\text { strip }\end{array}$ & $\begin{array}{c}\text { Deflection } \\
\text { measured } \\
{[\mathrm{mm}]}\end{array}$ & $\begin{array}{c}\text { Deflection } \\
\text { calculated } \\
{[\mathrm{mm}]}\end{array}$ & $\begin{array}{c}\text { Deviation } \\
{[\%]}\end{array}$ \\
\hline 1 & 1,285 & 1,761 & 27 \\
\hline 2 & 1,455 & 1,564 & 7 \\
\hline 3 & 1,745 & 1,523 & $-14,6$ \\
\hline 4 & 1,570 & 1,741 & 98 \\
\hline
\end{tabular}




\subsection{Conclusion of static analysis}

For temperature loads, the produced models behave in accordance with the measured values. Comparing the deflections measured in the static loading test and calculated in the static analysis of the structure, the different parts of the bridge have differently accurate results. For the vault 3 a very good agreement was reached, for the vault 4 there are more marked differences. The conclusions of the static analysis show the functionality of the joints of the structure and the inconsistency of the material properties for the individual parts of the bridge.

\section{DYNAMIC LOADING TESTS}

To excite the forced oscillation of the bridge structure in shapes close to the theoretical oscillation mode shapes (mode shapes cannot be excited, it is a dimensionless mathematical fictitious shape), a hydraulic INSET vibration exciter (Figure 7) was used in the harmonic excitation mode. During the tests, the excitor was placed on the bridge (or on the tramway) in three positions. These positions were designed for measurements on individual vaults in spans 1, 2 and 5. The theoretical location of the exciter was half the span of the bridge in the longitudinal direction and on the tramline. At these locations, the excitation was in the position for horizontal transverse excitation (relative to the axis of the bridge) and for vertical excitation.

The bridge response to the dynamic loading was monitored in a detailed network of

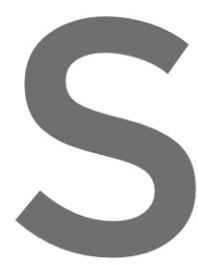
measurement points in which the oscillation velocitie horizontal, transverse and horizontal longitudinal directions. served to measure the oscillation of the bridge fields, the installation a The measurements
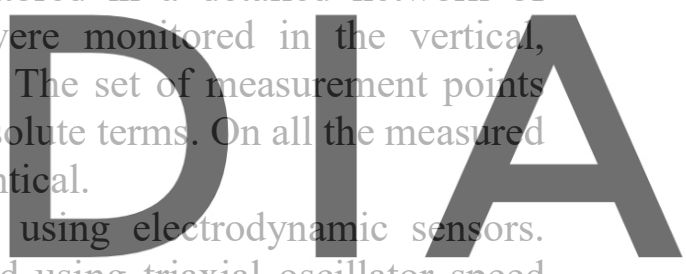

Dynamic deflections (or vibration velocities) were measured using triaxial oscillator speed

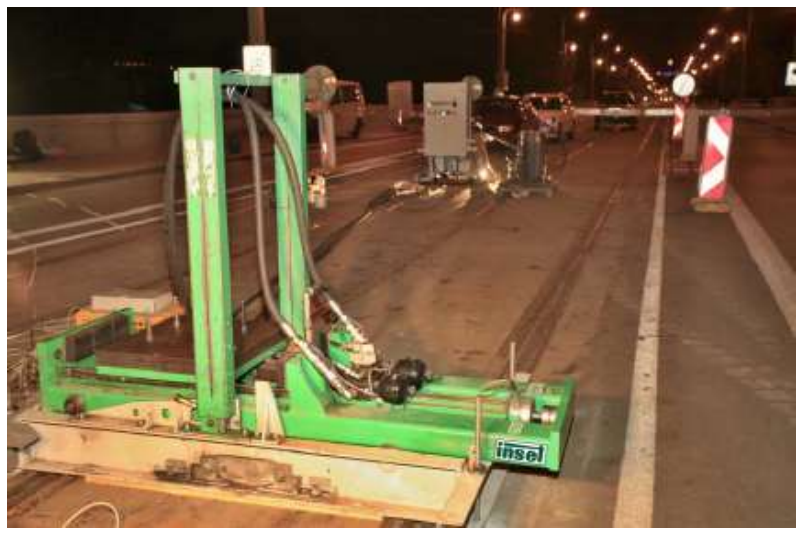

Figure 7: The vibration exciter installed on the tramline 


\subsection{Conclusion of dynamic loading test}

The bearing structure of the tested vaults has behaved flexibly before, during and after the dynamic loading and no new unexpected defects or faults have been detected. The amplitude frequency spectra obtained on individual vaults do not show sharp spectral peaks, as is common with compact constructions, but the spectral peaks are rounded and include narrow bandwidth. This effect is due to the effect of different geometric and material characteristics and boundary conditions on individual vaults and their individual parts, both in the longitudinal and transverse directions.

Detected oscillation shapes corresponding to their own oscillation shapes. At the lowest frequencies we find global shapes where the main supporting structure oscillates as a whole, or as two units in portions separated by a vertex joint. Only at higher frequencies vault strips are separated, which then oscillate in pairs.

\section{DYNAMIC ANALYSIS OF THE STRUCTURE}

The modal analysis model is based on diagnostic measurements on the design and the dynamic load test. The loading test was performed for the vault 1,2 and 5. The vaults 1 and 5 are influenced by the frame constructions, which would burden the other model with another unknown and increase the calculation inaccuracy. For this reason, modal analysis deals with vault number 2. The model was created in Scia Engineer 15 software.

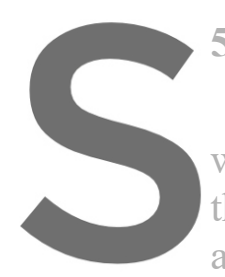

\subsection{Model description \\ Construction of the model \\ with a mod-ulus of elasticity E \\ thickness. The top and toe join

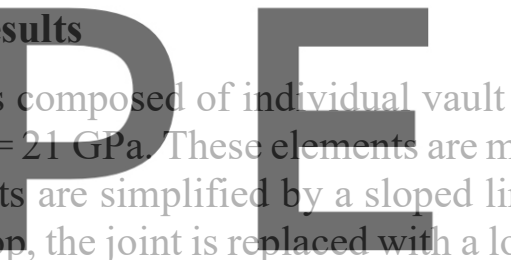

at the heel of the vault. At the ton, the joint is re
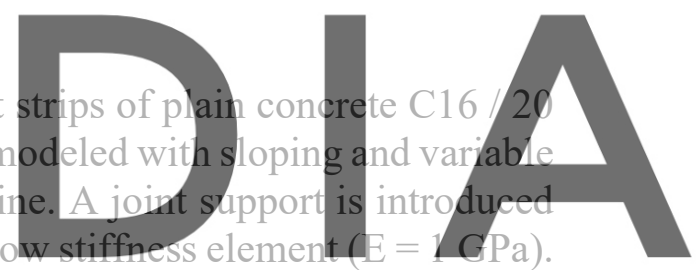

The wall elements forming the front wall $(\mathrm{E}=19 \mathrm{GPa})$ and the overhang $(\mathrm{E}=3 \mathrm{GPa})$ are

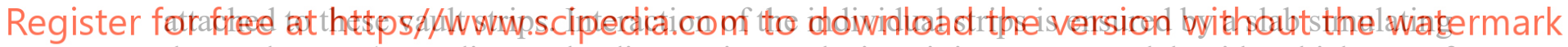
the road cover (according to the diagnostic conclusions it is a concrete slab with a thickness of $500 \mathrm{~mm}$ and bituminous cover with a thickness of $200 \mathrm{~mm}, \mathrm{E}=10 \mathrm{GPa}$ ). This slab is provided with boundary conditions ensuring the continuity of the structure (non-moving joints). In this model, where the upper slab behaves like a strained membrane that limits the oscillation of the structure, two identical oscillations have been found for measured frequencies of 7.23 and 11.92 $\mathrm{Hz}$ (Figure 8, 9).

In case we for this model partially release the boundary conditions for the top plate by inserting resilient supports with a stiffness of $100 \mathrm{MN} / \mathrm{m}^{2}$, the loosening of the wall linkage over the top joint vertically (flexible support with a stiffness of $100 \mathrm{MN} / \mathrm{m} 2$ ) and by adjusting the stiffness of the left $19 \mathrm{GPa}$ ) and right $(23 \mathrm{GPa})$ of the half of the arc to take into account the diversity of materials and possible discontinuities, we obtain another consistent shape of oscillation of the structure for the measured $6.46 \mathrm{~Hz}$ (Figure 10). 


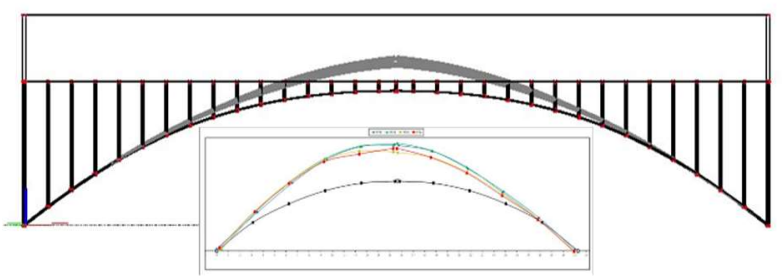

Figure 8: Measured and calculated oscillation shape for $7.23 \mathrm{~Hz}$

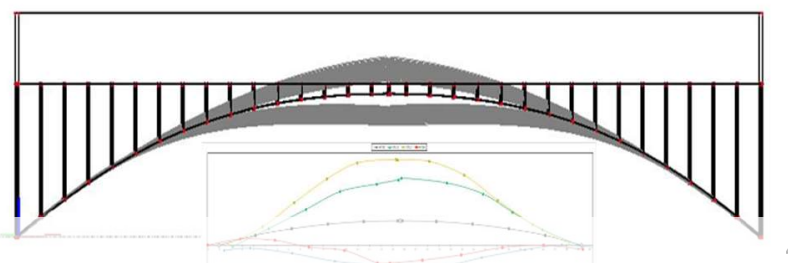

Figure 9: Measured and calculated oscillation shape for $11.92 \mathrm{~Hz}$

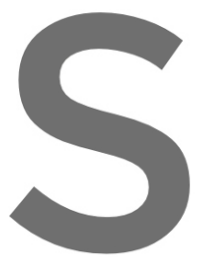

\subsection{Conclusion of dynamic analysis}

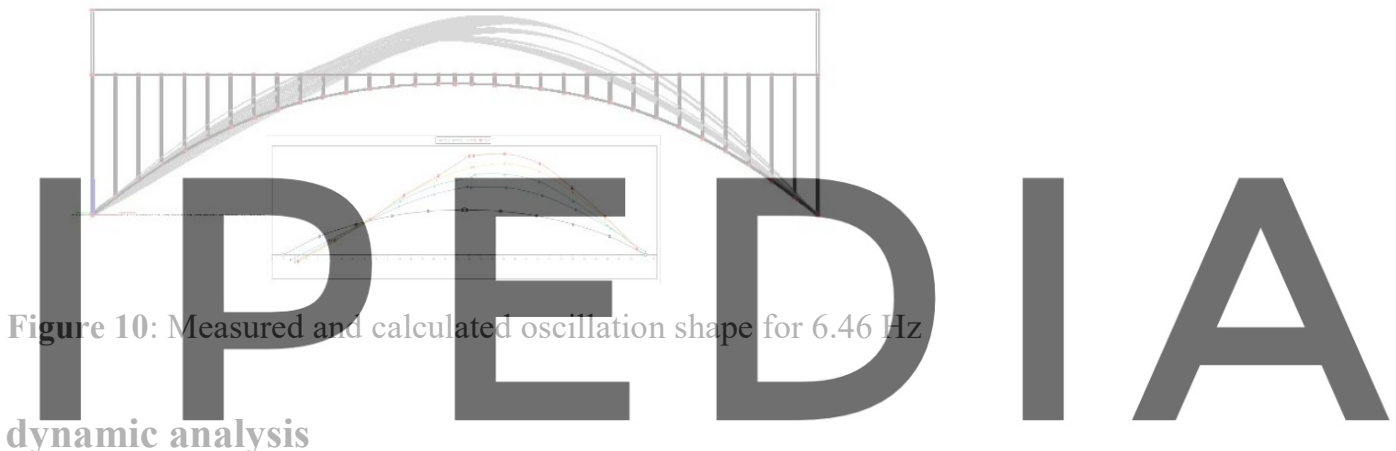

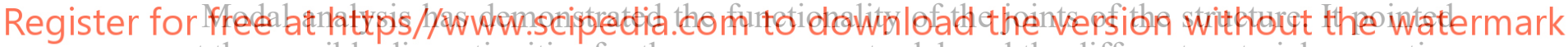
out the possible discontinuities for the upper concrete slab and the different material properties in the various portions of the supporting strips of the plain concrete vault. The results of the dynamic analysis of the vaults are heavily influenced by the complexity of the entire structure, particularly upper concrete slab and the upper filling.

Table 3 compares the measured and calculated frequencies and their deviation is determined according to [1]. Consequently, the calculated frequencies show a good match with the frequencies measured.

$$
\Delta=\frac{f_{\text {theor }}-f_{\text {obs }}}{f_{\text {theor }}} \cdot 100
$$

Table 3: Frequency comparison

\begin{tabular}{ccc}
\hline $\begin{array}{c}\text { Frequencies } \\
\text { measured } \\
{[\mathrm{Hz}]}\end{array}$ & $\begin{array}{c}\text { Frequencies } \\
\text { calculated } \\
{[\mathrm{Hz}]}\end{array}$ & $\begin{array}{c}\text { Deviation } \\
{[\%]}\end{array}$ \\
\hline 6,46 & 6,64 & 2,7 \\
\hline 7,23 & 8,5 & 14,9 \\
\hline 11,92 & 10,46 & $-13,9$ \\
\hline
\end{tabular}




\section{RECONSTRUCTION OF BRIDGE}

The project deals with the possibilities of reconstruction of the vault part of the Liben Bridge, frame structures and staircases in terms of static operation and durability. In the framework of the vault part, it focuses on two basic problems of the bridge, the solution of increasing the bearing capacity of vault arched strips and increasing the bearing capacity of foundation pillars.

For any bridge work to be used in accordance with current standards in the City of Prague, two basic requirements must be observed:

- $\quad$ static reliability and design safety with specified design load carrying capacity;

- durability and lifetime of the structure.

For this reason, the works were focused on the possibilities and ways to meet these two basic requirements also in the case of the main bridge V009 of the Liben region, even in the case of a cultural monument, i.e. in order to preserve as much existing structures as possible.

From diagnostics and static analyzes is obvious, that it is necessary to either perform a complex and highly demanding reconstruction aimed at the extensive static solution of the noncompliant parts of the bridge, or the construction of a completely new bridge without using the existing supports and pillars as planned in the 2005 project according to the required load (including tramway operation in both directions).

Ensuring the durability of the materials as well as the bridge according to the requirements of the current standards will be ensured only by building a new bridge. In the case of complex reconstruction, it must be assumed that such a lifetime cannot be guaranteed by any remediation

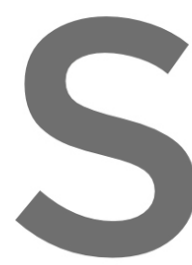
methods.

\subsection{The vault part of the Bridge}

The resulting variant of the reconstruction, which seems ensure the static reliability and
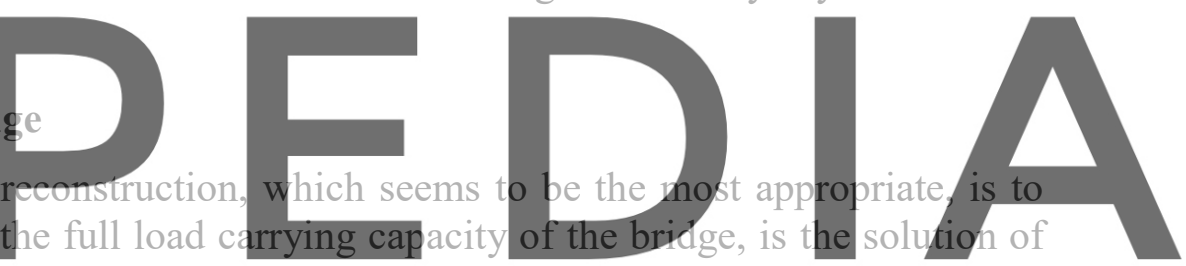
strengthening existing vaults with additional concrete layer of UHPFRC (Ultra-High

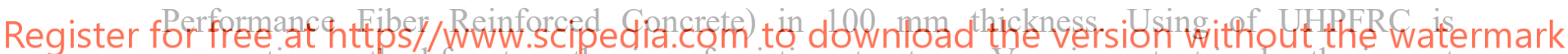
perspective method for strengthening of existing structures. Very important is also the impact of the bond between UHPFRC and steel reinforcement in coupling surface.

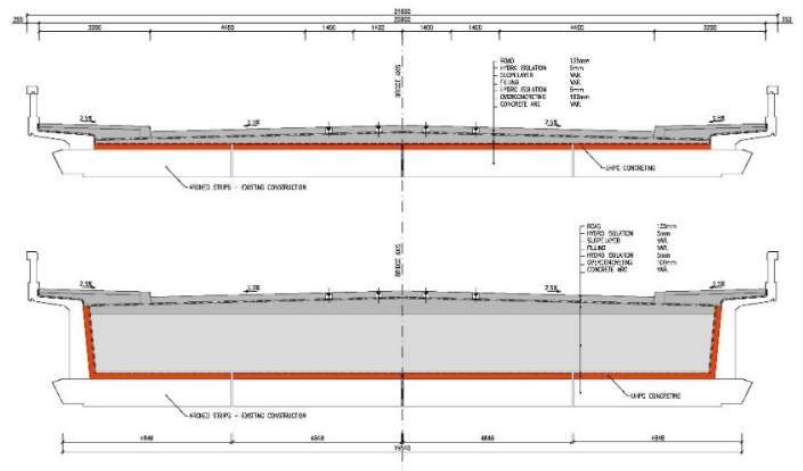

Figure 11: Cross section of the bridge at the top and at the foot of the vault. The UHPFRC layer is marked in red. 
Designed reinforcement of the existing vault belts of the Libeň Bridge by an over concreting of $100 \mathrm{~mm}$ thick UHPFRC layer.

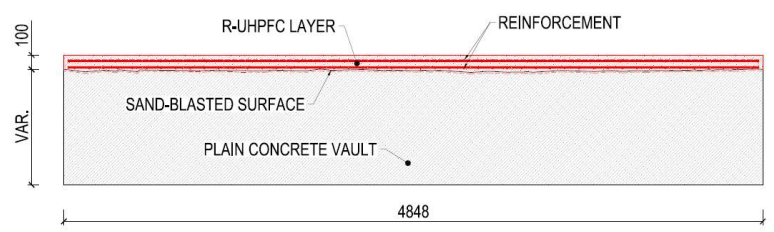

Figure 12: Cross section of reinforced arched strip of Libeň Bridge

Table 4: Comparison of cross-sectional characteristics before and after reinforcement

\begin{tabular}{lccc} 
& area $\left[\mathrm{m}^{2}\right]$ & $\begin{array}{c}\text { centre of gravity from } \\
\text { the lower face }[\mathrm{m}]\end{array}$ & $\begin{array}{c}\text { Moment of } \\
\text { inertia }\left[\mathrm{m}^{4}\right]\end{array}$ \\
\hline Original cross-section & 3,878 & $0,5 * \mathrm{H}$ & 0,207 \\
\hline Ideal cross-section & 5,008 & $0,63 * \mathrm{H}$ & 0,385 \\
Comparison & $+29,1 \%$ & $0,13 * \mathrm{H}$ up movement & $+86,0 \%$
\end{tabular}

From the calculated results, it is evident that by over-concreting only $100 \mathrm{~mm}$ of R-UHPFRC material, the cross-sectional characteristics of the arched belts will be significantly improved

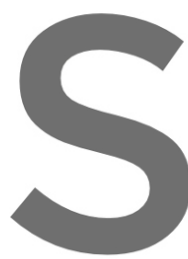
due to its unique materi results are calculated
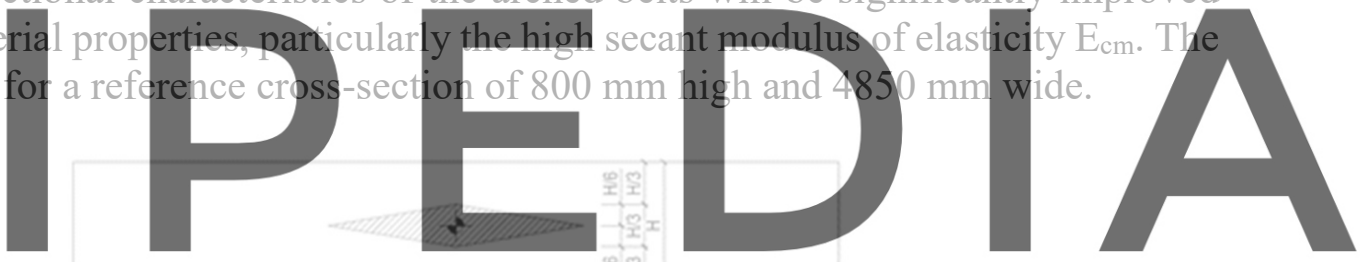

Register for free at https//www.scipedia:comotodowkallaad-stateversion without the watermark

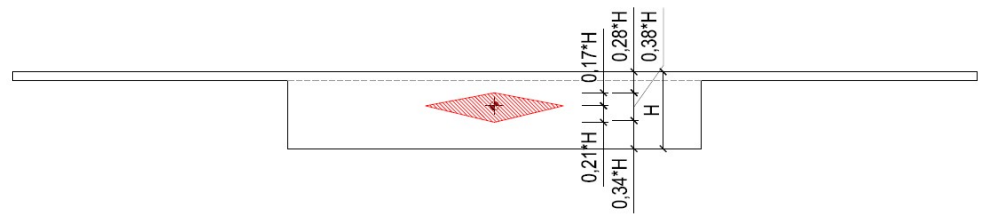

Figure 14: Core of ideal reinforced cross-section

The disadvantage of the reinforcement of the structure is the introduction of the load from the shrinkage of the over concreting. In the case of the possibility of symmetrical double-sided reinforcement of the structure, this load is not a problem, as the result of these forces will be approximately normal compressive force, which is generally well tolerated by concrete structures. In the more frequent case of the possibility of one-sided reinforcement of the structure (over concreting on the upper surface), it is necessary to consider the additional bending moment stress of the supporting structure. 


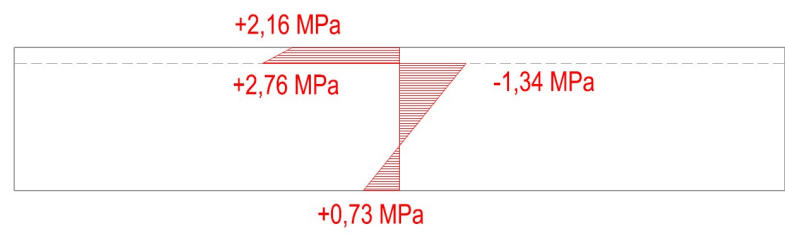

Figure 15: Effects of excess shrinkage on total stress in cross-section

Thickening of the cross-section will increase the cross-sectional area of the cross-section. In the direction of the vertical $\mathrm{Z}$ axis (bending around $\mathrm{Y}-\mathrm{Y}$ ) the core height is increased by $29.6 \%$.

The results of the diagnostics of vault foundations show that the structure of the foundation is strongly degraded by sulphate corrosion and regarding its reinforcement it is necessary to proceed with its repair. This repair is based on covering the existing foundation with reinforced concrete envelope.

Unfortunately, this repair does not stop but only reduces the sulphate corrosion process. Predicting the rate of sulfate corrosion without long-term monitoring is not possible. In the case of a complex reconstruction, it will be necessary to monitor and test the condition of the concrete foundations and pillars for a long time. As part of the proposal, it will also be necessary to set up a plan for tracking and monitoring the bridge for reconstruction.

\subsection{The frame part of the Bridge}
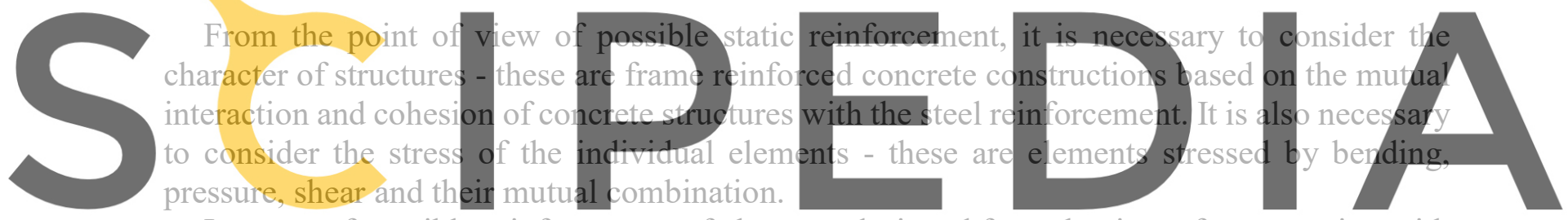

In terms of possible reinforcement of elements designed from the time of construction with

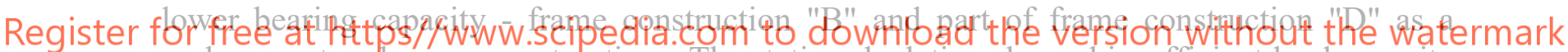
replacement make new constructions. The static calculation showed insufficient load capacity of the whole structure not only in the local section. Possible reinforcement eg external reinforcement or concreting seems to be technically almost impossible to do, by enhancing the construction they would lose their original character, shape and appearance.

From the point of view of the overall repair, it is recommended the complete replacement of the frame constructions. Regarding the existing damaged frame constructions, it is not reasonably possible to statically increase the durability, functionality and stability of these structures.

\section{CONCLUSIONS}

Static and dynamic load tests of a considerable scale were carried out on the structure, in which the behavior of the structure of plain concrete vaults was verified. Based on the results, numerical models were developed to perform a static and dynamic analysis of the structure.

A static load test and static analysis has demonstrated the functionality of the structure. It pointed out the possible discontinuities for the upper concrete slab and the different material properties in the various portions of the supporting strips of the plain concrete vault. The dynamic load test and dynamic analysis of the structure confirmed these findings. 
From diagnostics and static analysis, it has been shown that for the operation of the bridge to the required load according to the currently valid standards it is necessary to carry out either: complex and demanding reconstruction focused on the extensive static solution of the non-compliant parts of the bridge, including the stabilization of the foundations, or

- building a completely new bridge

From obtained results is clear that by reconstruction based only on partial static interventions and "cosmetic" repairs of the surfaces without substantial and complex static intervention (ideally see be-low), the bridge will only be operated with permanent traffic restrictions.

Ensuring the durability of the bridge according to the requirements of the current standards (design value of at least 100 years) can only be provided by building a new bridge. In the case of a complex reconstruction, it is to be assumed that such a lifetime will not be permanently secured by any remediation methods. But regarding the reconstruction of historic buildings this is predictable and usual. With this fact it is necessary to count in the specification of the repair, the requirements for the final parameters of the reconstruction and the subsequent maintenance of the bridge.

Based on the acquired knowledge and information on the state of the bridge and the possibilities of its reconstruction and repairs, the following main conclusions can be found:

The load carrying capacity of the bridge required by the currently valid ČSN 736222 can be ensured in two ways:

- The complex reconstruction of the bridge, which includes the following major interventions:

- Securing the foundations of the vault bridge (fixing in terms of sulphurous corrosion).

- Replacement of two central vault strips (three-joint arches) in all five vaults with new reinforced concrete belts (again three-joint arches).

- Repair and rehabilitation of the structures and their surfaces, including putting them into the required appearance.

- Secondary surface protection to increase service life and durability.

- Complete replacement of frame structures and staircases with new constructions, including the appearance of concretes in staircases.

- Implementation of new waterproofing, drainage systems, embankments and bridge superstructure.

- Regular specialized and long-term (permanent) monitoring of the bridge as well as degradation processes in the foundations and evaluation of the results found in relation to the state - the functional capability of the object.

- $\quad$ Construction of a completely new bridge without the use of the underground structure (foundations and supports) of the existing bridge.

The reconstructed bridge will need to be more closely monitored. It can be assumed that the maintenance and operation costs of the reconstructed bridge will be higher compared to the new construction.

Acknowledgements. Theoretical basis for the presented results were obtained under the support of the research project GAČR 17-22796S. 


\section{REFERENCES}

[1] Mourek, J., Tej, P., Kral, J., Kolisko, J. “Assessment of structural condition of steel bridge in Brandys nad Orlici." MATEC Web of Conferences 107, doi: 10.1051/matecconf/201710700003

[2] Tej, P., Kral, J., Tejova, A., Markova, J.. "Long-Term Monitoring of a Composite SteelConcrete Bridge on the Prague Ring Road." Applied Mechanics and Materials, doi: 10.4028/www.scientific.net/AMM.617.13

[3] Čech, J., Tej, P., Kolísko, J., Král, J. 2017. "Structural condition assessment of the bridge in Ostrava." MATEC Web of Conferences 107, doi: 10.1051/matecconf/201710700001

[4] Kněž, P., Čech, J., Tej, P., Blank, M. 2017. "Assessment of structural condition of Libeň Bridge." MATEC Web of Conferences 107, doi: 10.1051/matecconf $/ 201710700002$

[5] Knez, P., Tej, P., Citek, D., Kolisko, J. 2017 "Design of footbridge with double curvature made of UHPC", IOP Conference Series-Materials Science and Engineering 246, doi: 10.1088/1757-899X/246/1/012042

[6] Kolísko, J., Čítek, D., Tej, P., Rydval, M. 2017 "Production of footbridge with double curvature made of UHPC", IOP Conference Series-Materials Science and Engineering 246, doi: 10.1088/1757-899X/246/1/012009

[7] Kolisko, J., Cech, J., Tej, P., Knez, P. 2017 "UHPC panels utilized as permanent formwork of in-situ cast reinforced concrete deck bridges.” IOP Conference Series-Materials Science and Engineering 246, doi: 10.1088/1757-899X/246/1/012043

[8] Tej, P., Kolisko, J., Knez, P., Cech, J. 2017. "The Overall Research Results of Prestressed I-beams Made of Ultra-high Performance Concrete." IOP Conference Series-Materials Science and Engineering 246, doi: 10.1088/1757-899X/246/1/012051

[9] Tej, P., Kněž, P., Kolísko, J., Vráblík, L. 2017. "Modal analysis of cable-stayed UHPC bridge." MATEC Web of Conferences 107, doi: 10.1051/matecconf/201710700007

[10] Blank, M., Tej, P., Kolísko, J., Vráblík, L. 2016. "Design of Experimental Suspended Footbridge with Deck Made of UHPC." MATEC Web of Conferences 77, doi: 10.1051/matecconf/20167708005

[11] Pokorny, P., Tej, P., Kouřil, M. 2017. "Evaluation of the impact of corrosion of hot-dip galvanized reinforcement on bond strength with concrete - A review", Construction and Building materials 132, p. 271-289.

[12] Pokorny, P., Tej, P., Szelag, P. 2016. "Chromate conversion coatings and their current application", Metalurgija 55, p. 253-256.

[13] Pokorny, P., Tej, P., Szelag, P. 2016. "Discussion about magnesium phosphating", Metalurgija 55, p. 507-510.

[14] Brozek, V, Kolisko, J. et all. 2015."Boronized stainless steels with zirconia coatings", Metal 2015:24th International Conference on Metallurgy and Materials, Tanger Ltd, p. $1069-1074$ 